\title{
CHANGING MINDSET, PERCEPTIONS, LEARNING, AND TRADITION: AN "ADAPTIVE TEACHING FRAMEWORK" FOR TEACHING MUSIC ONLINE \\ Brad Merrick
}

Melbourne Conservatorium of Music, The University of Melbourne, Australia, E-mail: brad.merrick@unimelb.edu.au

This paper is based on the reflections and experiences from a participant researcher perspective and explores the creation of an inventory of core pedagogical components, called the adaptive teaching framework (ATF), for use in online teaching. This was developed as part of a graduate music teaching program (MTP) across more than 20 tertiary subjects. It involves a series of reflections, descriptions, discussion points, and suggestions, which specifically reference related learning theory, content review, modification of learning design, and pedagogy that were considered during the implementation of a new learner management system (LMS) platform (Canvas) at the start of 2020. Amid the initial phase of implementation, staff and students were also required to move suddenly into a fully online learning environment, as the COVID-19 pandemic took hold and the subsequent lockdown removed all face-to-face teaching, an essential part of the MTP that included music performance, classroom pedagogy, curriculum design, research, and ensemble performance, as examples of some of the wide-ranging subject areas. These two significant changes (LMS implementation and the COVID-19 pandemic) occurred concurrently, which heightened both the immediacy and demand for adaptive teaching design within a fully implemented online program. The paper overviews the development of the ATF, in response to these mandated changes, just three weeks into Semester One, 2020. The methodology employed was self-study and aspects of critical reflective practice, whereby the researcher reflected on the intersection of technology and 21st century learning in music education, drawing on established literature, research, and emerging learning models combined with creative pedagogies.

KEY WORDS: mindset, tradition, online learning, adaption, change, curriculum assessment, teaching framework, pedagogy, innovation, creativity

\section{INTRODUCTION AND BACKGROUND}

In recent months, COVID-19 has impacted the world, and online technologies have experienced unprecedented access and demand. This has forced education systems and jurisdictions around the world to move quickly to adapt, modify, and reassess the 
application of online learning as a necessary conduit in a highly connected and technology-dependent world. This unexpected event has forced instructors and educators to move beyond their traditional, discipline-specific content and skills, delving into the realm of emerging 21 st century capacities, such as collaboration, creativity, transferable skills, and problem solving as they modified the graduate music teaching program (MTP). There was also the necessity to engage with more creative modes of assessment during the redesign (Soland et al., 2013) to compliment the innovation in teaching. In essence, the adaptive teaching framework (ATF) emerged from the impact of a learner management system (LMS) institutional change, combined with the need to respond rapidly to the COVID-19 pandemic. The framework looks to connects several discrete-yet related-areas to assist the design of online teaching. These areas include established learning theory (self-regulation, mindset, and related motivational constructs), relevant research into online and remote learning, and emerging 20th century teaching practice, combined with a range of experiences that were integral in the design and teaching of a tertiary program during this time.

In responding to the crisis, and developing the ATF, many attributes and behaviors from the entrepreneurial skill set were embedded within the online learning design process, including innovation, problem solving, self-confidence, and creativity (Heinonen and Poikkijoki, 2006). The unprecedented urgency provided an unexpected, but timely, opportunity to investigate, evaluate, and research the currency of the teaching and learning that existed in the MTP, assessing how knowledge and skill had been taught previously, and exposing the modifications required to transition to a fully online teaching environment.

It was the confluence of two separate, yet overlapping, changes that initiated the need for significant entrepreneurial behavior. These influenced the learning design and mode of subject delivery as all learning transitioned to a fully online mode in a matter of weeks. Importantly, these events forced the pedagogical lens onto key areas related to teaching online, including curriculum and assessment, providing a unique chance to modify pedagogy and student learning experiences within the tertiary setting (Smith and Brown, 2005).

It is important to acknowledge that at the same time that these events unfolded, the online communication software, Zoom, reported an increase from 10 to 200 million daily users during a three-month period up to and including April 2020, confirming its use as the main communication software in thousands of educational institutions and businesses around the world during this time (Yuan, 2020). The purpose of this paper is to highlight the need for the ATF as well as demonstrate how it can be practically applied when teaching online. 


\subsection{Related Theories and Learning Models}

The key element involved in successful learning online was the ability to provide rich experiences that allowed the participants to demonstrate their "understanding" continuously, where the creation and confirmation of knowledge, skill, and subsequent application, were at the center of the learning design (Perkins, 2004). Most importantly, the environment required the creation of opportunities for students to demonstrate their understanding in multiple formats, across different contexts and settings. The ATF embraces the large body of research related to self-regulated learning (SRL) (Zimmerman, 2002) and the phases and sub-processes of self-regulation (performance, self-reflection, and forethought). Through adaptive use of curriculum and assessment structures aligned with SRL, combined with creative preparation and design, the students were invited to interact more frequently, while developing their critical thinking and independence as learners, and increasing their participation through the development of the process (selfefficacy and motivation) combined with strategies (i.e., observation, goal-setting, and revision) within a SRL-centered online environment (Zimmerman, 1990; Zimmerman and Kitsantas, 2002).

There were key elements involved in transferring to a new LMS. These actions included evaluating existing teaching, using research to inform practice, and shifting artifacts online. First, was the opportunity to evaluate the key aspects of learning design (curriculum) and pedagogy (teaching practice), and the way they worked to complement one another. The second step involved drawing on existing and emerging research that connected remote learning and technology (King et al., 2019a). The third step, and necessary action, involved relocating a large proportion of the material from all subjects into the asynchronous space, thus increasing student accessibility to the learning material at any time, which was viewed as being beneficial for students (Chen et al., 2019).

Armed with the desire to employ more flexible teaching methods, certain aspects of a blended learning approach that had been used during the initial LMS transition to Canvas, continued to be applied with the knowledge that it increased the ease of access to resources, interactive activities, and communication tools (Chen et al., 2019; Merrick and Mifsud, 2015). The consideration of emerging research into the effectiveness of technology-based assessment (Sweeney et al., 2017), and the connection it provided to the overall quality of course delivery (Smidt et al., 2017), was important. Similarly, there was a need to ensure that the new online environment for teaching music utilized both synchronous and asynchronous technologies to engage meaningfully with the students (Yamagata-Lynch, 2014). Policy and documentation related to future-focused 21st century learning capacities [Organisation for Economic Co-operation and Development (OECD), 
2018] informed the inclusion of essential skills for the students to develop and demonstrate in their learning journey.

\section{CONSIDERATIONS FOR THE TRANSITION TO A NEW LEARNING MANAGEMENT SYSTEM}

Given the dramatic increase in the use of online learning during COVID-19, and the author's considerable experience of using LMS in different educational settings, it was both timely and necessary to ask the following questions: What resources are required to teach online? How can this be achieved successfully within the timeframe?

The predominant use of mobile devices and the emergence of a large body of research in the field (Lai, 2020) necessitated considerable thought in order to ensure any tasks and activities that were developed could be accessed by learners across all technologies, settings, and locations. This involved reviewing the most effective experiences that contributed to improved teaching, often by challenging the existing pedagogy of the instructors involved (Kaliisa et al., 2019). Another important area that required consideration as part of the ATF was ensuring that all types of media resources-including the quality of visual, audio, and multimedia-maintained suitable functionality within the LMS such that there was reliability from a user experience view. This degree of focus proved important since it ensured that the quality of sound, images, and video were consistent before being placed online (King et al., 2019b).

Another important consideration was fostering student alignment with learning, combined with their engagement and inclusivity (McLoughlin, 2001) through tasks that developed autonomy, competence, and intrinsic motivation among the students. These processes drew on previous research undertaken into online learning and self-determination theory (Jeno et al., 2019). Here, the ATF guided the teachers to embrace rigorous, quality learning experiences and purposeful assessment modes; the aim being to create accessibility and authenticity within the online learning process.

Critical to the ATF was contextualized analysis and revisioning of practice, moving from the traditional, didactic modes of delivery that had been aligned with the content-driven delivery in the previous LMS (Blackboard). The intention was the creation of a more appealing and inviting mode of interaction and delivery as the students entered the online space. To attain this outcome, the visual representation of file systems in older archived shells were creatively modified and changed to provide more visually interesting and interactive experiences for the students. Underpinning these design features, the ATF placed increased emphasis on designing tasks that aligned with the phases of SRL (Zimmerman, 2002), combined with purposeful tasks that invited students to shift beyond their comfort zone, challenging their understanding of effective learning. This required 
considerable modification of existing teaching strategies combined with the continuous creation and introduction of new pedagogies, whether it was peer teaching of instruments via Zoom, an online research task via a real-time survey, or the analysis of an orchestral rehearsal on the Internet. As part of the ATF, the instructor continuously adopted a "facilitator role," redirecting the students' thinking, interactions, and creativity as they worked online, looking to embrace new opportunities that expanded their previous experience. The purpose was to develop tasks that demonstrated effective teaching and learning and explored growth mindset (Dweck, 2006), whereby the students were challenged to move beyond their established perceptions of their ability as learners.

The ATF "learning process" (see Appendix A, Fig. A1) highlights how the use of "communication" and "collaboration" are essential "activators of learning" through the creation of inclusive communities that positioned student "care" and "well-being" as a priority among online learners in the 21st century; not dissimilar to those experiences of connection associated with music making in community settings (Croom, 2015). This was particularly important, given the isolation that the COVID-19 scenario created. The rapid shift to a fully online program highlighted the need for-and placed an increased focus on-the development of social and emotional skills (OECD, 2018). With a predominance of musicians and music teachers, a large amount of the online material and learning tasks developed, specifically using activities that involved musical participation (performing, watching, listening, and composing music) as a conscious attempt to promote well-being (Krause et al., 2018; Lamont, 2012).

Student engagement was considered critical within the process. The focused use of teacher agency and authenticity were important components of classes and presentations (whether synchronous or asynchronous in delivery), enabling meaningful connection and interactions between the instructors and the students within the MTP (OECD, 2018). Previous research (Kaschub and Smith, 2014) also confirmed that the use of creative pedagogy and interactions among students contributes to the development of their sense of agency and musical stewardship as learners.

\section{CONTEXT AND DESIGN DESCRIPTION}

\subsection{Focusing on the Why}

The mode of teaching music via online technology has been an accepted practice for many years, although it has not always been adopted within these learning environments (Dye, 2016; Johnson, 2017), despite having been promoted as an accepted 21st century online pedagogy. In other subject areas it has also received minimal acceptance as a pedagogy, encountering difficulty during adaption into teaching practice as new innovations have arrived (Boehm, 2007). Although many types of technology-based 
training approaches have been offered historically, there is still a reluctance for many teachers to engage in this area (Johnson, 2017; Merrick, 1997). This opportunity to evaluate, modify, and annotate the existing MTP was a significant window to examine and employ renewed emphasis on the use of online learning as the main conduit for the teachers and students in this setting. It also provided opportunities for the instructor to connect a newly designed online learning environment to the course outcomes, which were linked to the training of future music teachers.

Targeted question designs that informed the analysis process were central in identifying pre-existing perceptions that were prevalent in the current MTP delivery. These included the following:

- How do you currently teach in your institution?

- Does your approach to teaching align with the course outcomes and the learners' attributes and needs?

- Do you use varied modes of delivery for different components of the course (i.e., performance, research, aural, teaching practice, etc.)?

- What modes of pedagogy/teaching strategies do you commonly use and why are these preferable?

- What are your "go to" methods of instruction that you use when teaching with technology?

- How does your LMS integrate media and incorporate audio and visual resources?

- What aspects of the LMS design or use have you changed during the LMS transition period and COVID-19 pandemic?

- What and why did you change? Was it successful?

- How did the new design of the learning sequence within the LMS enhance the experience for the students?

- Has your confidence in using technology for online teaching increased during this time?

These questions were found to be useful within the ATF, providing an essential learning opportunity for the instructors to search and understand how they viewed their own teaching, and to identify the things they had modified during this time. This was a powerful process since it ensured the link between the purposes of the online learning design was reflected in the learning outcomes for the subjects within the MTP. From this perspective, 
examining all of these domains was essential in developing the inventory provided in the ATF. The areas examined were the following:

- Existing modes and approaches to teaching - the established and traditional modes of delivery commonly observed and modeled among instructors;

- Favored teaching modes and strategies (i.e., lectures, questioning, demonstrations, and approaches to feedback);

- Organization and sequence of learning (i.e., content, activities, interaction, performance, assessment, and forums);

- Risk talking and innovation in teaching (successful or unsuccessful), identifying changes, or modification to teaching in an online learning environment;

- Self-reflection and SRL related to pedagogy and practice;

- Teacher confidence and creativity; and

- The types of behaviors and interactions demonstrated by students, relative to their degree of enjoyment and understanding within the learning environment.

By using questions in this way, the evaluation focused on essential factors associated with successful online teaching, identifying strengths and weaknesses for further attention. The adoption of a cyclical mode of continuous self-reflection as an instructor highlighted the value of continual review, adaption, and modification to ensure that the online learning experience aligned with student needs. This regularly involved changes in the online teaching delivery in real time, which were critical learning opportunities for the designer. It was important to continually trial various approaches, and to assess which ones were the most functional and flexible for the tertiary students situated in a virtual world. This often involved designing ideas in the LMS "sandpit," where new teaching activities were developed and tried before their implementation into a subject area as part of the MTP.

Whether it was the use of a pre-recorded screencast, a live performance demonstration, or a review of a Zoom video from the previous week, the key element was taking risks as a teacher. The temptation of shifting traditional, didactic delivery into a technology-enhanced environment was an initial solution; therefore, it was critical for the instructor to employ the various asynchronous and synchronous activities that were found to work effectively in different course areas, combining these approaches with possible face-to-face (virtual) learning as well, drawn from earlier blended learning experiences. At this time in history where online access to movies, music, messages, and a plethora of media-based 
information consumption occupies our daily existence, using a variety of pedagogies to maintain connection and engagement among students was found to be critical.

As a final reflection, the most successful teaching episodes created during this time fostered student agency, provided rigor and choice, enhanced student focus, and developed their capacities and skills for the future (OECD, 2018).

\section{OVERVIEW OF SPECIFIC LMS CHANGES AND ESSENTIAL DESIGN CONSIDERATIONS IN THE ATF}

The following subsections provide descriptions of the six key focus areas that influenced online teaching, outlining the essential factors that contributed to the design of the ATF (see Appendix A).

\subsection{Focus on Visual, Audio, Media, and Resource Organization}

Critical to the renewed LMS design was the introduction of effective, consistent organization within the Canvas Shell such that the way the learner viewed the content, accessed the materials, and engaged in course-related activities preempted student thinking, creativity, and engaged them in the learning process from their first entry into the LMS area. Examples of these types of activities included having regular video announcements (rather than text announcements) and releasing new subject material on the same day of the week in order to create predictability for the students. The most effective processes involved using short, focused overviews that could be digested easily and revisited multiple times if needed. Here, students could adopt an "anywhere" or "anytime" approach to their learning online (Martin et al., 2010).

Similarly, the links to readings, upcoming tasks, and preparation work were often created and delivered to the students using varied modes, rather than just uploading a traditional sequence of word documents or pdf files for download and review. Modeling innovative teaching practice with different forms of media, combined with creativity applications of these resources, were invaluable. Regular demonstrations of these pedagogies in the online classes were implemented to encourage students to connect, think, reflect, and use innovative and purposeful strategies in their own future teaching. These approaches aligned with policy that advocated for the inclusion of creative thinking and application in all learning tasks, in order to improve student agency and diversity, foster aspects of metacognition, enhance inter- and intra-personal skills, and develop social engagement (OECD, 2019).

\subsection{Foster "Growth Mindset" and Creativity}

Essential to the redesign and development of this ATF was the integration of collaborative learning opportunities among students with their peers, where they were able to 
experience their learning through different contexts. This allowed students to observe others doing things in different ways and ask questions of their peers; whether it was reading a published summary of a discussion, commenting on a written reflection, creating an evaluation while reviewing an online performance, or the recording of a verbal explanation in a two-minute video or audio log, these types of experiences heightened students' engagement while moving them outside their comfort zone in many instances. In this context, it was beneficial for the mindset of the learners to be constantly challenged through the diversity of online approaches and experiences.

Importantly, as the students became more familiar with-and aware of-the online approach, their sense of confidence and their willingness to connect and work with others in different ways were accepted as normal processes. Simple teaching strategies, such as ensuring that each Zoom breakout session used student combinations, ensured the learners were constantly immersed into new collaborative environments, refining their ability to communicate and exploring new opportunities as a team of learners rather than as individuals. As a result of the newly developed pedagogy, the online teaching environment provided many new and creative teaching approaches that were not commonly used in the face-to-face classroom (pre-COVID-19). Through the forced shift to an online design, all students became regular participants in a learning community that challenged their mindset and perceptions.

\subsection{Develop a Clear Sequence of Learning}

The shift to the online teaching environment during the COVID-19 pandemic meant the redesign of the LMS continued in conjunction with the continued demand for online teaching during the semester. It was apparent that a variety of different pedagogies and approaches were being employed within the course. An essential component of the course design was providing clarity through a connected experience. A series of focus questions were developed and used to guide learning activities, resources, and online tasks. This was a valuable planning strategy that ensured the learning experiences and assessment tasks were all aligned with the course focus. An important consideration was ensuring that sufficient time was provided to develop, trial, review, and implement innovative teaching strategies as they emerged.

To assist with the forecasting and clarity of communication for students, the instructors would develop, create, and release material to the LMS shell early, often two weeks prior to classes, which allowed students to gain access to important material. This attention to detail and planning well ahead of delivery facilitated the opportunity for staff to think more broadly about their subject learning and find learning connections that had previously not 
been possible. The learning tasks became more visible and connected by aligning the development of new material with the following questions:

- Why are we learning (which included the broad aims, context of the learning, intended purpose, overarching curriculum link, and connection to the course)?

-What are we learning (which was linked to the specific learning intentions and the outcomes required to be understood)?

- How will we learn (which included the selection of teaching strategies; different environments; and resources, including technologies, studio learning opportunities, and classroom experiences)?

-When will we learn (which included the sequence of learning tasks and the development of understanding linked to the ongoing assessment and feedback)?

- Where will we learn (which included the location of the learning experience to be used, such as a review of a chapter published online, an analysis of a rehearsal or masterclass hosted on Vimeo of YouTube, a group lesson using Zoom, or the observation of a virtual music lesson using video-conferencing software)?

\subsection{Embed Self-Regulated Learning in Online Teaching}

Since the researcher had previously undertaken research on the use of SRL in a music technology setting and observed the way it contributed to learning (Merrick, 2006), this was included as an integral component in the overall design and placement of learning experiences. Through ongoing reference to the phases and sub-processes of selfregulation (Zimmerman, 2002), and before attempting similar tasks again in a cyclic manner, the online tasks were designed with consideration of each of the following three phases: the performance phase (doing), the self-reflection phase (review, judgment, and adaption), and the forethought phase (planning, self-efficacy, and strategy). By employing an established SRL theory as a reference the students continuously engaged in a range of tasks that encouraged them to be independent learners, while importantly developing skills in self-reflection and self-assessment. The students became more aware of their level of understanding (skills and knowledge), while also developing the ability to modify behavior and refine their approach to learning when they did not understand something (Zimmerman, 1990). As the use of SRL continued within the online setting, many students displayed increased engagement with the LMS, which appeared to enhance their capacity to learn in this type of setting (Broadbent, 2016). 
There was also sustained emphasis on the creation of works that allowed the students to demonstrate their level of understanding and application (i.e., a speech, essay, short movie, composition, or presentation) within the performance phase. This would be followed by purposeful review in the self-reflection phase (i.e., self-assessment of a music performance, peer evaluation of an online presentation, observation of a video or task relative to a rubric, or detailed commentary as part of an online forum about his/her own creative work). Students often presented trail tasks before the formal submission of a task. This allowed students to review, plan, think, and prepare strategically for the next attempt in the learning cycle, relative to their level of motivation and engagement. In essence, they were engaging with formative feedback that was contributing to their learning (Black and Wiliam, 2003).

As these sub-components of the ATF developed, an important area emerged for consideration, which included the incorporation of varied technologies, devices, and connection modes within the online environment. As students uploaded a range of work such as a PDF of an essay, a hand-written image from a tablet, or a short movie on their phones, it became important to provide equitable access across the multitude of different technologies being used to present the subjects within the program. It was common for the teacher to develop small recorded messages or movies, and to spend considerable time creating different formats (AIF, MP3, Wav, Mov, and MP4 files) to cater to different download speeds, access points, and variations among the technologies owned by the students. This was another example of teachers and instructors applying self-regulatory processes to ensure that the online learning met the needs of all students enrolled during this time.

\subsection{Initiate Responsive Teaching Practice}

As we move to the end of the critical reflection about this experience (Benade, 2015), and revisit the thinking that contributed to the development of the ATF to assist online teaching, it is important to emphasize that teachers develop their capacity to stay in the moment during classes. As participants in the various interactions and feedback processes that emerge, they need to ensure that they respond to student needs in both timely and meaningful ways. One example that highlighted this approach involved engaging with, and employing, combinations of assessment processes, i.e., written annotations uploaded on an electronic document as an online review; uploading a completed rubric to explain marking allocations; uploading a completed rubric to explain marking allocations combined with providing a video or audio file that describes aspects of successful learning in the task; or uploading a completed rubric to explain marking allocations combined with a description of areas needing further development. The ability to be responsive was 
essential in this type of environment, where students are simultaneously living their lives online as well as learning online.

Other responsive teaching strategies that were found to be useful included uploading a brief screencast of a traditionally extended lecture, such that it only included 20-30 minutes of targeted material and links. Combined with a series of provocations and thinking points for students to consider in advance, this proved to be successful and was similar to the flipped approach, where material for the learning session is viewed prior to the students meeting together (Chen et al., 2019; Kazanidis et al., 2019; Merrick and Mifsud, 2015).

Part of this responsive teaching required leading from the front, and taking risks, which involved instructors forecasting the intended learning and expectations to the students in regular announcements and bulletins. Similarly, it was quite common to develop a small vignette of real-time uploads and resources (e.g., a chord chart, brief instructional steps on a video for guitar hand position, or an audio example that highlights a particular technique), while the students were simultaneously engaged in an online peer teaching session within the virtual teaching studio. Engaging students required the facilitator of learning to be a coach, instructor, and motivator; this was essential in the development of teaching practice during this time, ensuring that the pedagogy always supported the student in the learning environment at that point in time.

As the COVID-19 scenario continued, a key component of the graduate MTP involved students observing other music teachers in studios and schools. Since schools were also closed at the time, this scenario forced instructors to respond and innovate. Here, new approaches were developed whereby teaching students had their instrumental lessons observed by other teachers and students via Zoom, or taught music lessons to school students themselves using online technologies while being observed by their supervisor remotely as part of their teaching practice. The students were able to complete their placement requirements as they became music teachers, actively creating and applying adaptive teaching approaches themselves. This was valuable and exposed them to a range of different adaptive teaching scenarios they may never have experienced in a more traditional setting.

\subsection{Create Authenticity through Student Voice}

This self-study (Samaras, 2011) highlighted the importance of listening and really hearing the students as they participated in the learning process. Their needs had to be at the center of the learning design; otherwise, the learning was not sustained. In this context, the ATF included the opportunity for student voice to be expressed through a range of online tasks. Examples of tasks included asking each student to contribute a small 
paragraph to the chat in Zoom, completing a small online survey about their experiences, and encouraging students to share feedback about the tasks they enjoyed or aspects of the teaching they would like modified in a different way.

Through the ongoing incorporation of student voice, there was a sense of authenticity and agency that emerged in the learning process for all involved. These factors influenced engagement and participation, heightening the sense of community felt among the students and teachers. Importantly, this also contributed to their ongoing sense of connection and well-being.

\section{FINAL REFLECTIONS AND RECOMMENDATIONS}

This experience of reshaping online learning for a tertiary, graduate MTP during a time of LMS change and the COVID-19 pandemic highlighted that adaptive and creative approaches to learning are essential for the development of successful online learning.

The ATF (see Appendix 1) provides an inventory that draws on educational research and emerging capacities of 20th century learners, while guiding the design and purpose behind the learning. It can be used to connect both learning and implementation such that the design incorporates a range of authentic and purposeful tasks in an online world. As we move beyond the COVID-19 pandemic toward 2030, the challenge will be to ensure that the alignment of these emerging capacities (i.e., flexible learning, dynamic curriculum, and increased focus on the needs of each individual) continue to be nurtured alongside increased confidence and the continued application of online learning.

This framework reinforces the need to have a continual self-reflection cycle at the center of both the teaching and learning processes, combined with sound knowledge of the learning intentions, outcomes, and assessment processes that will be developed and applied. As noted throughout the discussion, the intentional placement of student care, ongoing clarity of communication, and sense of community need to remain central to the experience.

This ATF is not meant to be a conclusive research finding. It has been developed with the hope that the information included will assist other teachers and instructors as they engage in the craft of online teaching, providing guidance and a series of processes that have emerged from a real-life teaching scenario. Importantly, the writer plans to continue developing and refining this ATF design to ensure continued adaptivity as new considerations arise. This will include shifting to more innovative and creative teaching practices, where risks are encouraged and mistakes are frequent. The reflections and reallife experiences shared throughout this paper provide strong support for the need to change the mindset, perceptions, learning, and tradition that has dominated the online space for many years, and allow the experiences of recent times to guide and inform our use of online learning in meaningful ways-now and into the future. 


\section{REFERENCES}

Benade, L. (2015). Teachers' critical reflective practice in the context of twenty-first century learning. Open Review of Educational Research, 2(1), 42-54. https://doi.org/10.1080/ 23265507.2014.998159

Black, P. and Wiliam, D. (2003). 'In praise of educational research': Formative assessment. British Educational Research Journal, 29(5), 623-637. https://doi.org/ 10.1080/0141192032000133721

Boehm, C. (2007). The discipline that never was: Current developments in music technology in higher education in Britain. Journal of Music, Technology and Education, 1 (1), 7-21. https://doi.org/10.1386/jmte.1.1.7_1

Broadbent, J. (2016). Academic success is about self-efficacy rather than frequency of use of the learning management system. Australasian Journal of Educational Technology. https://doi.org/10.14742/ajet.2634

Chen, M. A., Hwang, G., and Chang, Y. (2019). A reflective thinking-promoting approach to enhancing graduate students' flipped learning engagement, participation behaviors, reflective thinking and project learning outcomes. British Journal of Educational Technology, 50(5), 2288-2307. https://doi.org/10.1111/bjet.12823

Croom, A. M. (2015). Music practice and participation for psychological well-being: A review of how music influences positive emotion, engagement, relationships, meaning, and accomplishment. Musicae Scientiae, 19(1), 44-64. https://doi.org/10.1177/ 1029864914561709

Dweck, C. S. (2006). Mindset. the new psychology of success. New York: Ballantine Books.

Dye, K. (2016). Student and instructor behaviors in online music lessons: An exploratory study. International Journal of Music Education, 34(2), 161-170. https://doi.org/10.1177/ 0255761415584290

Heinonen, J. and Poikkijoki, S. (2006). An entrepreneurial-directed approach to entrepreneurship education: Mission impossible? Journal of Management Development, 25(1), 80-94. https://doi.org/10.1108/02621710610637981

Jeno, L. M., Adachi, P. J. C., Grytnes, J.-A., Vandvik, V., and Deci, E. L. (2019). The effects of m-learning on motivation, achievement and well-being: A self-determination theory approach. British Journal of Educational Technology, 50(2), 669-683. https://doi.org/10.1111/bjet.12657

Johnson, C. (2017). Teaching music online: Changing pedagogical approach when moving to the online environment. London Review of Education, 15(3), 439-456. 
Kaliisa, R., Palmer, E., and Miller, J. (2019). Mobile learning in higher education: A comparative analysis of developed and developing country contexts: Mobile learning in higher education. British Journal of Educational Technology, 50(2), 546-561. https://doi.org/10.1111/bjet.12583

Kaschub, M. and Smith, J. (Eds.). (2014). Promising practices in 21st century music teacher education. Oxford, UK: Oxford University Press. https://doi.org/10.1093/ acprof:oso/9780199384747.001.0001

Kazanidis, I., Pellas, N., Fotaris, P., and Tsinakos, A. (2019). Can the flipped classroom model improve students' academic performance and training satisfaction in higher education instructional media design courses? British Journal of Educational Technology, 50(4), 2014-2027. https://doi.org/10.1111/bjet.12694

King, A., Prior, H., and Waddington-Jones, C. (2019a). Connect resound: Using online technology to deliver music education to remote communities. Journal of Music, Technology and Education, 12(2), 201-217. https://doi.org/10.1386/jmte_00006_1

King, A., Prior, H., and Waddington-Jones, C. (2019b). Exploring teachers' and pupils' behaviour in online and face-to-face instrumental lessons. Music Education Research, 21 (2), 197-209. https://doi.org/10.1080/14613808.2019.1585791

Krause, A. E., Davidson, J. W., and North, A. C. (2018). Musical activity and well-being: A new quantitative measurement instrument. Music Perception, 35(4), 454-474. https://doi.org/10.1525/mp.2018.35.4.454

Lai, C. (2020). Trends of mobile learning: A review of the top 100 highly cited papers. British Journal of Educational Technology, 51(3), 721-742. https://doi.org/10.1111/ bjet. 12884

Lamont, A. (2012). Emotion, engagement and meaning in strong experiences of music performance. Psychology of Music, 40(5), 574-594. https://doi.org/10.1177/ 0305735612448510

Martin, F., Tutty, J. I., and Su, Y. (2010). Influence of learning management systems selfefficacy on e-learning performance. I-Manager's Journal on School Educational Technology, 5(3), 26-35. https://doi.org/10.26634/jsch.5.3.1086

McLoughlin, C. (2001). Inclusivity and alignment: Principles of pedagogy, task and assessment design for effective cross-cultural online learning. Distance Education, 22(1), 7-29. https://doi.org/10.1080/0158791010220102

Merrick, B. (2006). The relationship between self-efficacy and self-regulated behaviour within a secondary school music technology based creative learning environment [Doctoral dissertation, University of New South Wales]. http://unsworks.unsw.edu.au/fapi/ datastream/unsworks:1082/SOURCE1?view=true 
Merrick, B. M. (1997). Teaching teachers to use technology in the classroom-A model for inservice training. In V. Weidenbach (Ed.), Conceptualising Music Education Research. Proceedings of the XVIII Annual Conference (p. 4). Sydney: AARME.

Merrick, B. and Mifsud, A. (2015). Innovative and inspired learning environments in music education: Technology and the blended classroom. In J. Rosevear (Ed.), Educating for life. ASME XXth National Conference Proceedings. (p. 7). Victoria: ASME.

Organisation for Economic Co-operation and Development (OECD). (2018). The future we want. OECD. http://www.oecd.org/education/2030-project/about/documents/

Organisation for Economic Co-operation and Development (OECD). (2019). PISA 2021 creative thinking framework. https://www.oecd.org/pisa/publications/PISA-2021-creativethinking-framework.pdf

Perkins, D. (2004). Knowledge alive. Educational Leadership, 62(1), 14-19.

Samaras, A. P. (2011). Self-study teacher research: Improving your practice through collaborative inquiry. Thousand Oaks, CA: SAGE Publications.

Smidt, E., Li, R., Bunk, J., Kochem, T., and McAndrew, A. (2017). The meaning of quality in an online course to administrators, faculty, and students. Journal of Interactive Learning Research, 28(1), 23.

Smith, J. and Brown, A. (2005). Building a culture of learning design: Reconsidering the place of online learning in the tertiary curriculum. ASCILITE 2005 Balance, Fidelity, Mobility: Maintaining the Momentum, 10.

Soland, J., Hamilton, L. S., and Stecher, B. M. (2013). Guidance for educators. Measuring 21st Century Competencies, 70.

Sweeney, T., West, D., Groessler, A., Haynie, A., Higgs, B. M., Macaulay, J., MercerMapstone, L., and Yeo, M. (2017). Where's the transformation? Unlocking the potential of technology-enhanced assessment. Teaching and Learning Inquiry, 5(1), 1-13. https://cora.ucc.ie/handle/10468/3907

Yamagata-Lynch, L. C. (2014). Blending online asynchronous and synchronous learning. The International Review of Research in Open and Distributed Learning, 15(2). https://doi.org/10.19173/irrodl.v15i2.1778

Yuan, E.S. (2020) A message to our users. https://blog.zoom.us/a-message-to-our-users/

Zimmerman, B. J. (1990). Self-regulated learning and academic achievement: An overview. Educational Psychologist, 25(1), 3-17. https://doi.org/10.1207/ s15326985ep2501_2

Zimmerman, B. J. (2002). Becoming a self-regulated learner: An overview. Theory into Practice, 41(2), 64-70. https://doi.org/10.1207/s15430421tip4102_2 
Zimmerman, B. J. and Kitsantas, A. (2002). Acquiring writing revision and self-regulatory skill through observation and emulation. Journal of Educational Psychology, 94(4), 660 -668. https://doi.org/10.1037/0022-0663.94.4.660

\section{APPENDIX A}

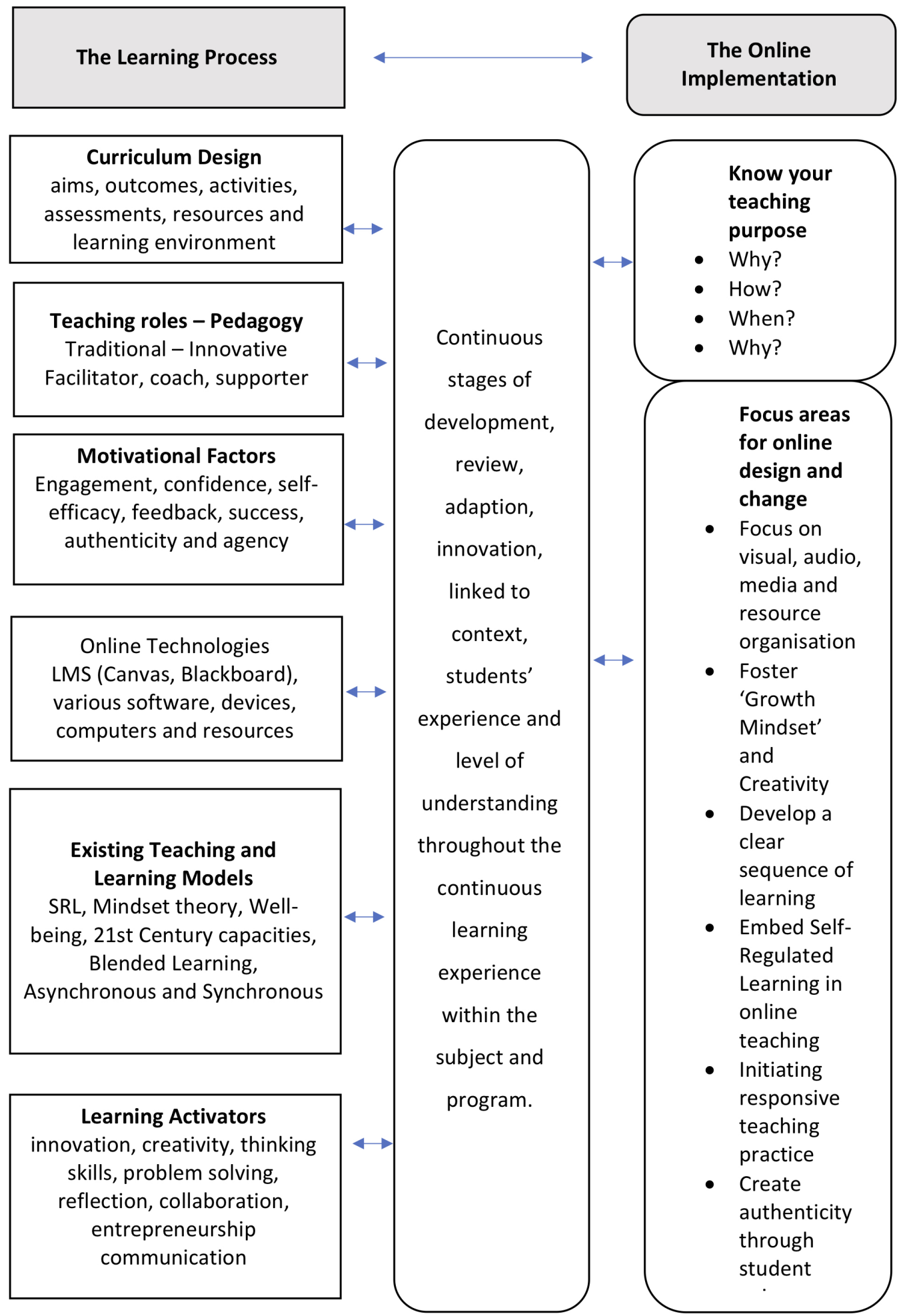

FIG. A1: Adaptive teaching framework (initial overview), version 1 